\title{
Spectroscopic Determination of Chromium(VI) during the Reduction of Chromium(VI) to Chromium(III)
}

\author{
THOMAS A. MAXCY, G. PAUL WILLHITE, DON W. GREEN, ${ }^{*}$ and \\ KRISTIN BOWMAN MERTES \\ Department of Chemical and Petroleum Engineering (T.A.M., G.P.W., D.W.G.); and Department of Chemistry and Medicinal \\ Chemistry (K.B.M.), University of Kansas, Lawrence, Kansas 66045
}

\begin{abstract}
Reduction of chromium(VI) to chromium(III) by thiourea between pH 3.0 and 5.5 is a key aspect of the chromium(VI)/thiourea/polyacrylamide gel polymer system used in enhanced oil recovery processes. A method has been developed to determine chromium(VI) concentration during the reduction of chromium(VI) to chromium(III) in this $\mathrm{pH}$ range. The reduction reaction is run in the presence of an acetic acid/sodium acetate buffer which reacts with the chromium(III) produced and prevents the formation of a brown precipitate which forms in the absence of the buffer. With interference from the precipitate eliminated, chromium(VI) concentration is determined from the visible absorbance of the reaction mixture and the unique molar absorptivity spectra of the five chromium species present in the reaction mixture. An average error of approximately $1 \%$ between known and measured chromium(VI) concentrations was demonstrated over a chromium(VI) concentration range from 0.0005 to $0.0025 \mathrm{M}$.
\end{abstract}

Index Headings: Reduction of chromium(VI); Analysis of chromium(VI); Computer algorithm.

\section{INTRODUCTION}

A gel polymer system composed of chromium(VI), thiourea, and polyacrylamide is used by the petroleum industry in enhanced oil recovery processes. In the 3.0 to $5.5 \mathrm{pH}$ range, chromium(VI) is reduced by thiourea to chromium(III), which reacts with polyacrylamide to form a crosslinked polymer gel. ${ }^{1,2}$ To understand more fully this gel polymer system, one needs a reaction rate model for the reduction of chromium(VI) by thiourea.

The reduction of chromium(VI) to chromium(III) has been studied by several researchers. Reviews of early work using a variety of reducing agents are available, ${ }^{3,4}$ as are papers on the reduction of chromium(VI) by thiols other than thiourea. ${ }^{5-13}$ Reduction of chromium(VI) by thiourea in strongly acidic solutions has been used to standardize solutions of thiourea. ${ }^{14-17}$ Olatunji and McAuley ${ }^{18}$ studied the rate of reduction of chromium(VI) by thiourea for $\mathrm{pH}$ levels between 0.0 and 0.6 and developed a reaction rate model. Kinetic studies of the reduction of chromium(VI) by thiourea from $\mathrm{pH} 3.0$ to 5.5 have not been performed.

Concentration vs. time data are required in order to develop a reaction rate model. Two problems not addressed in previous work make the determination of chromium(VI) concentration difficult in solutions containing chromium(VI) and chromium(III) under acidic conditions. First, if the $\mathrm{pH}$ of the reaction mixture is between 4.5 and 6.0 , a brown precipitate containing chromium(VI) and aquated chromium(III) forms and inter-

\footnotetext{
Received 23 November 1990; revision received 24 February 1991.

* Author to whom correspondence should be sent.
}

feres with spectroscopic analytical techniques. Second, chromium(VI) in $\mathrm{pH} 3.0$ to 5.5 solutions is present as bichromate $\left(\mathrm{HCrO}_{2}^{-}\right)$, dichromate $\left(\mathrm{Cr}_{2} \mathrm{O}_{7}{ }^{2-}\right)$, and chromate $\left(\mathrm{CrO}_{4}{ }^{2-}\right) .{ }^{19,20}$ The presence of these three chromium(VI) species and two chromium(III) species, with unique but overlapping absorption spectra, makes spectroscopic determination of chromium(VI) concentration a nontrivial matter.

In the work reported here new analytical procedures are introduced to overcome the difficulties. A coordinating buffer system composed of acetic acid and sodium acetate is added to the reaction mixture to prevent precipitation. Chromium(VI) concentration is determined with the use of the molar absorptivities of the five chromium species, which were determined experimentally, and measurements of the molar absorptivity of the reaction mixture at several different wavelengths. This information is combined in a computer algorithm to calculate the chromium(VI) concentration of the reaction mixture.

\section{THEORY}

Precipitates Containing Chromium(VI) and Chromium(III). A finely divided brown precipitate forms when chromium(VI) is reduced by thiourea at $\mathrm{pH} 4.5$ and above. A similar brown precipitate was reported during the reduction of chromium(VI) by thiosulfate in the 6.0 to 6.5 pH range. ${ }^{6}$ The reaction mixtures contain aquated chromium(III) and chromium(VI) at $\mathrm{pH} 4.5$ and above. Aquated chromium(III) is known to first form oligomers and then form a gray precipitate in this $\mathrm{pH}$ range. ${ }^{21}$ Aquated chromium(III) and chromium(VI) are known to form brown precipitates containing both chromium(III) and chromium(VI) in this $\mathrm{pH}$ range. ${ }^{22}$ The brown precipitate that forms during the reduction reaction is probably a combination of chromium(VI) and aquated chromium(III) monomer or aquated chromium(III) oligomers.

Studies have been reported in which an acetic acid/ sodium acetate buffer was used during the reduction of chromium(VI) by bisulfite ${ }^{23}$ and thiosulfate. ${ }^{6}$ In both cases the reaction mixtures contained chromium(VI) and chromium(III) in the 4.0 to $5.0 \mathrm{pH}$ range and there were no precipitates. Since the brown precipitate is believed to contain aquated chromium(III), it is presumed that running the reduction reaction in the presence of acetate leads to the reaction of aquated chromium(III) with acetate to form tris(acetato)chromium(III) ${ }^{24}$ and prevents formation of the precipitate. 
Chromium Species Present during the Reduction Reaction. When chromium(VI) is reduced in the presence of acetate buffer, the chromium(III) produced is initially present as aquated chromium(III), which reacts with the acetate buffer to form tris(acetato)chromium(III). ${ }^{24}$ Since both chromium(III) species are present in the reaction mixture, the absorbance of both species must be taken into account.

Three chromium species-bichromate, dichromate, and chromate-are present in solutions containing chromi$\mathrm{um}$ (VI) in the 3.0 to $5.5 \mathrm{pH}$ range. Equilibrium and stoichiometric relationships for the three species are presented in Eqs. 1-5 $5^{19,20}$ below:

$$
\begin{aligned}
& \mathrm{Cr}_{2} \mathrm{O}_{7}{ }^{2-}+\mathrm{H}_{2} \mathrm{O} \rightleftharpoons 2 \mathrm{HCrO}_{4}^{-} \\
& \mathrm{HCrO}_{4}^{-} \rightleftharpoons \mathrm{H}^{+}+\mathrm{CrO}_{4}{ }^{2-} \\
& K_{d}=\gamma_{1}\left[\mathrm{Cr}_{2} \mathrm{O}_{7}{ }^{2-}\right] / \gamma_{2}{ }^{2}\left[\mathrm{HCrO}_{4}^{-}\right]^{2} \\
& K_{a}=\gamma_{3}\left[\mathrm{H}^{+}\right] \gamma_{4}\left[\mathrm{CrO}_{4}{ }^{2-}\right] / \gamma_{5}\left[\mathrm{HCrO}_{4}^{-}\right] \\
& {[\mathrm{Cr}(\mathrm{VI})]_{\text {total }}=\left[\mathrm{HCrO}_{4}^{-}\right]+2\left[\mathrm{Cr}_{2} \mathrm{O}_{7}{ }^{2-}\right]+\left[\mathrm{CrO}_{4}{ }^{2-}\right]}
\end{aligned}
$$

where $\gamma_{i}$ (dimensionless) is the activity coefficient of the associated species. Infinite dilution equilibrium constants have been reported: $K_{d}$ (Eq. 3) as $35.0 \mathrm{M}^{-1}$ (see Ref. 19) and $K_{a}$ (Eq. 4) as $3.2 \times 10^{-7}$ M. ${ }^{20}$ An equation for $K_{d}{ }^{*} \gamma_{2}^{2} / \gamma_{1}$ as a function of ionic strength is available, ${ }^{25}$ and $K_{a}{ }^{*} \gamma_{5} / \gamma_{3^{*}} \gamma_{4}$ can be calculated from the infinite dilution equilibrium constant and estimates of the ionic activity coefficients. More fully protonated species, $\mathrm{H}_{2} \mathrm{CrO}_{4}$ and $\mathrm{HCr}_{2} \mathrm{O}_{7}^{-}$, are present in solutions below $\mathrm{pH}$ $3.0,{ }^{19,25}$ and tri- and tetrachromates have been reported in strongly acidic solutions containing very high concentrations of chromium(VI). In this work, solution $\mathrm{pH}$ was not below 3.0 , so that only absorbance due to bichromate, dichromate, and chromate must be taken into account.

Reduction of chromium(VI) to chromium(III) is a multi-step reaction. When chromium(VI) is reduced by thiols, the first step is believed to be the formation of a chromium(VI)/thiol complex. ${ }^{13}$ The amount of chromium(VI)/thiol complex present in a reduction reaction mixture depends on the rate of formation of the complex and the rate of further reaction of the complex. With some thiols, the rates of formation and further reaction are such that significant amounts of the intermediate complex are present in reduction reaction mixtures. ${ }^{10,13}$ When chromium(VI) is reduced by thiourea, the reducing agent of primary interest in this work, the concentration of the chromium(VI)/thiourea complex is apparently small, because absorbance due to the chromium (VI)/thiol complex was not observed. In this work chro$\operatorname{mium}(\mathrm{VI}) /$ thiol intermediates were assumed to be present only in small amounts, and their contribution to the absorbance of the reaction mixture was not taken into account.

Spectroscopic Determination of Chromium(VI). Beer's law relates the absorbance of a multicomponent solution at a given wavelength to the molar absorptivities and the concentrations of the individual species (Eq. 6):

$$
A_{\lambda}=\epsilon_{n, \lambda} b c_{n}
$$

where $A_{\lambda}$ (dimensionless) is the total absorbance at wavelength $\lambda(\mathrm{nm}) ; \epsilon_{n, \lambda}(\mathrm{L} / \mathrm{mol} \mathrm{cm})$ is the molar absorptivity of species $n$ (dimensionless) at wavelength $\lambda ; b(\mathrm{~cm})$ is the cell pathlength; and $c_{n}(\mathrm{~mol} / \mathrm{L})$ is the concentration of species $n$.

When chromium(VI) is reduced to chromium(III) in the presence of an acetate buffer the reaction mixture contains five absorbing species: bichromate, dichromate, chromate, aquated chromium(III), and tris(acetato)chromium(III). The chromium(VI) concentration of the reaction mixture can be determined from the absorbance of the solution and the molar absorptivities of the absorbing species by solving five simultaneous equations.$^{26}$ One option is to measure the absorbance of the solution at five wavelengths and solve five simultaneous equations generated from Beer's law (Eq. 6). A second option, used when the total chromium concentration of the solution is known, is to measure the absorbance of the solution at four wavelengths and use a chromium material balance (Eq. 7) as the fifth simultaneous equation:

$$
\begin{aligned}
{[\mathrm{Cr}]_{\text {total }}=} & {\left[\mathrm{Cr}\left(\mathrm{CH}_{3} \mathrm{COO}\right)_{3}\right]+\left[\mathrm{Cr}\left(\mathrm{H}_{2} \mathrm{O}\right)_{6}\right]+\left[\mathrm{HCrO}_{4}{ }^{-}\right] } \\
& +2\left[\mathrm{Cr}_{2} \mathrm{O}_{7}{ }^{2-}\right]+\left[\mathrm{CrO}_{4}^{2-}\right] .
\end{aligned}
$$

In either case the total chromium(VI) concentration of the solution is the sum of the estimated bichromate, the chromate, and twice the dichromate concentrations.

\section{EXPERIMENTAL}

Chemical and Equipment. All chemicals used were reagent grade and were used without further purification. Ionic strength was maintained at $0.35 \mathrm{M}$ with sodium chloride and sodium acetate so that the activity coefficients of the three chromium(VI) species would be essentially constant in the 0.001 to $0.006 \mathrm{M}$ total chromium(VI) concentration range. Solution $\mathrm{pH}$ was measured with a Corning flat-surface combination electrode and a Fischer Scientific Accumet Model $910 \mathrm{pH}$ meter and was adjusted with sodium hydroxide and acetic acid. Visible absorbance was measured on a Ciba Corning Diagnostics Corporation Gilford Response II spectrophotometer. Pairs of 2- and $10-\mathrm{mm}$ quartz cuvets were used with the pathlength for a given measurement, chosen so that the absorbance of the sample was between 0.18 and 0.90 absorbance units.

Chromium(VI) is carcinogenic and must be handled in such a way as to avoid contact with the body..$^{13}$ Solids and solutions containing chromium are hazardous wastes and must be disposed of properly.

Detection of Precipitate in Sample Reaction Mixtures. Prevention of the brown precipitate by the acetate buffer was tested on a series of reaction mixtures containing potassium dichromate, thiourea, sodium chloride, acetic acid, and sodium acetate. The absence of precipitate in the sample reaction mixtures was verified with the use of the following procedures: First, a $10-\mathrm{mL}$ sample of each reaction mixture was forced through a $0.1-\mu \mathrm{m}$ filter. Second, the 0.1- $\mu \mathrm{m}$ filter was examined for traces of the brown precipitate. Third, the visible absorbance of the filtered reaction mixture was compared to that of the unfiltered reaction mixture.

Determination of Molar Absorptivities. Of the species present in solution during the reduction reaction, only the species containing chromium [bichromate, dichromate, chromate, aquated chromium(III), and tris(ace- 


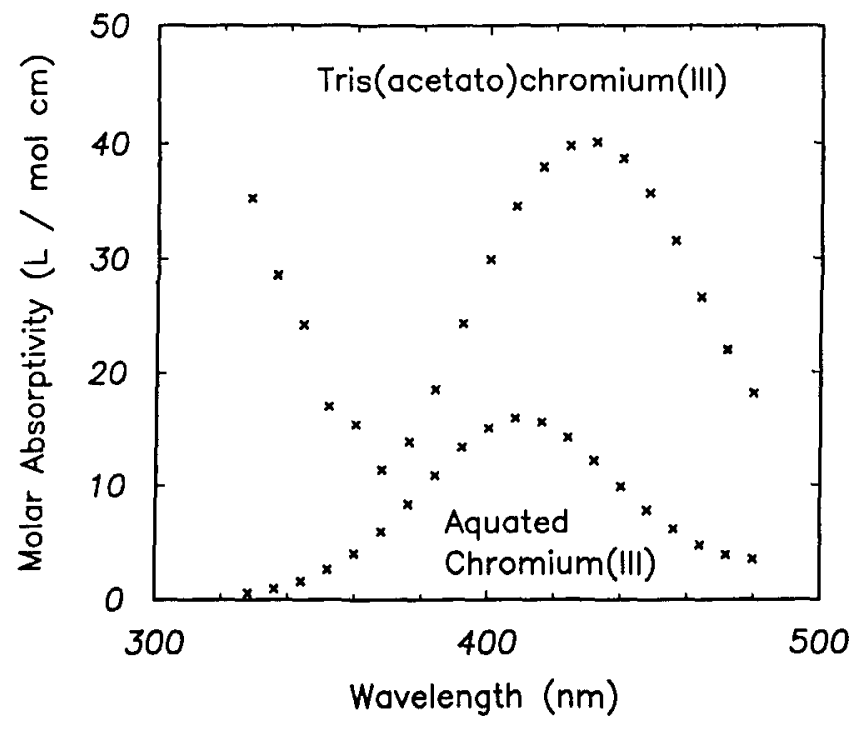

FIG. 1. Molar absorptivity vs. wavelength spectra for aquated chromium(III) and tris(acetato)chromium(III).

tato)chromium(III)] absorb significantly at visible wavelengths of from 328 to $800 \mathrm{~nm}$. Sodium chloride, acetic acid, and sodium acetate do not contribute to the absorbance of the reaction mixture in this wavelength range.

The molar absorptivities of aquated chromium(III) and tris(acetato)chromium(III) were determined from the absorbance of $0.5 \mathrm{M}$ solutions of chromic chloride and chromic acetate. In solutions at high $\mathrm{pH}$, chromium(VI) exists exclusively as chromate (Eq. 4). ${ }^{20}$ Consequently, the molar absorptivities of chromate were determined from the absorbance of a $0.0025 \mathrm{M} \mathrm{pH} 11.0$ solution of potassium dichromate.

Determination of the molar absorptivities of bichromate and dichromate was more complex because both compounds are present simultaneously in solution (Eqs. 3,5 ). The molar absorptivities of the two species were determined with the use of procedures similar to those of Tong and King ${ }^{25}$ and Linge and Jones. ${ }^{19}$ Nine chromium(VI) solutions were prepared, ranging in concentration from 0.001 to $0.006 \mathrm{M}$. Sodium chloride, acetic acid, and sodium acetate were used to adjust the ionic strength to $0.35 \mathrm{M}$ and the $\mathrm{pH}$ to 3.0 so that the only chromium(VI) species present would be bichromate and dichromate. Using Eq. 3, with a $K_{d}{ }^{*} \gamma_{2}{ }^{2} / \gamma_{1}$ value of 0.065 $\mathbf{M}^{-1},{ }^{25}$ and Eq. 5, we calculated the concentrations of bichromate and dichromate for each solution. The absorbance of each solution was measured, and the molar absorptivities of bichromate and dichromate at the desired wavelengths were found by fitting Eq. 6 , for two species, to the absorbance vs. concentration data of bichromate and dichromate.

Numerical Techniques for the Solution of Simultaneous Equations. Chromium(VI) concentration is calculated from a solution's measured absorbance at four wavelengths and the known total chromium concentration by solving five simultaneous equations. The equations were initially solved with the use of a version of Gaussian elimination ${ }^{27}$ available from IMSL ${ }^{28}$ as subroutine LEQIF. This numerical technique worked well for most so-

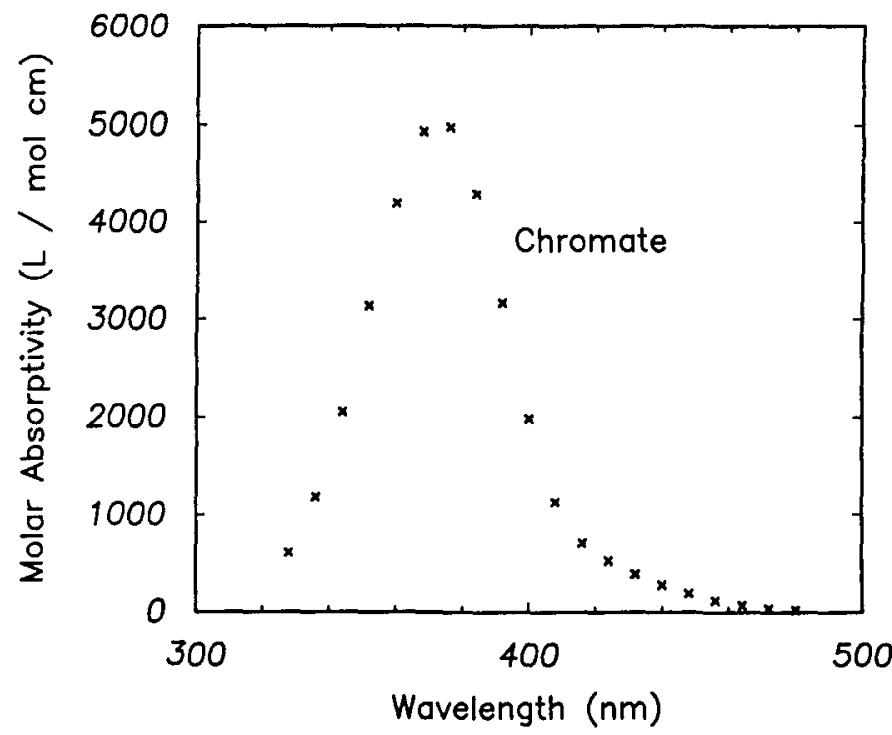

FIG. 2. Molar absorptivity vs. wavelength spectra for chromate.

lutions, but when the concentration of one of the five chromium species was small (e.g., less than 1\%) this technique occasionally assigned to that species a small negative concentration. In order to constrain the calculated concentrations to positive values, the equations were solved with the use of a constrained nonlinear regression technique available from $\mathrm{IMSL}^{28}$ as subroutine ZXMWD.

Verification of the Analytical Technique for the Determination of Chromium(VI). To evaluate the spectroscopic analytical technique, we prepared nine test solutions that had concentrations over the range typically found in the reaction mixtures of interest. The test solutions contained known amounts of both chromium(VI) $(0.0005$ to $0.0025 \mathrm{M}$, introduced as potassium dichromate) and chromium(III) (0.0005 to $0.0025 \mathrm{M}$, introduced as chromic acetate). The chromium(VI) concentration of each test solution was determined from its known total chromium concentration and its measured visible absorbance.

\section{RESULTS AND DISCUSSION}

Elimination of Precipitate Interference. No precipitate formed in a series of sample reaction mixtures that contained the acetate buffer. For example, a reaction mixture without the acetate buffer was prepared that contained potassium dichromate $(0.0025 \mathrm{M})$, thiourea $(0.020$ $\mathrm{M})$, and sodium chloride $(0.350 \mathrm{M})$ at $\mathrm{pH} 4.5$. After 4 days of reaction at $25^{\circ} \mathrm{C}$ the bottom and sides of the reaction container were covered with a fine brown precipitate that was easily isolated by passing the solution through a $1.0-\mu \mathrm{m}$ filter. A similar reaction mixture was prepared that contained potassium dichromate $(0.0025$ $\mathbf{M})$, thiourea $(0.020 \mathrm{M})$, sodium chloride $(0.300 \mathrm{M})$, acetic acid $(0.005 \mathrm{M})$, and sodium acetate $(0.05 \mathrm{M})$ at $\mathrm{pH}$ 4.5. After 4 days of reaction of $25^{\circ} \mathrm{C}$, no precipitate could be seen on the sides or bottom of the reaction container. Samples of the second reaction mixture were forced through a $0.1-\mu \mathrm{m}$ filter. No precipitate could be seen on 


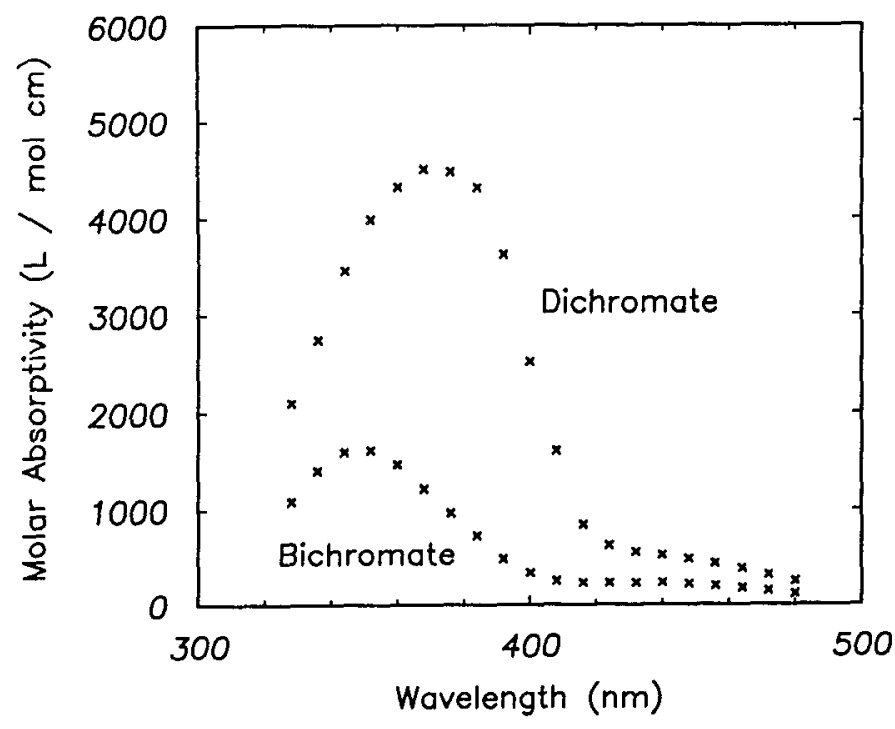

Fig. 3. Molar absorptivity vs. wavelength spectra for bichromate and dichromate.

the $0.1-\mu \mathrm{m}$ filter, and the visible absorbances of the filtered and unfiltered solutions were the same.

Molar Absorptivities of the Chromium Species. The molar absorptivity vs. wavelength spectra of aquated chromium(III) and tris(acetato)chromium(III) are shown in Fig. 1, that of chromate is shown in Fig. 2, and those of bichromate and dichromate are shown in Fig. 3. The molar absorptivity values for dichromate are per mole of $\mathrm{Cr}_{2} \mathrm{O}_{7}{ }^{2-}$; the absorptivity per mole of chromium is one half that presented in this work.

Absorptivity values at four wavelengths are used in the analytical technique. The first wavelength, $328 \mathrm{~nm}$, was selected because the absorptivity of tris(acetato)chromium(III) is greater than that of aquated chromium(III) and the absorptivity of chromate is less than the absorptivities of bichromate and dichromate. The second wavelength, $344 \mathrm{~nm}$, was selected because the absorptivities of bichromate and dichromate are similar to each other and less than the absorptivity of chromate. The third wavelength, $380 \mathrm{~nm}$, was selected because the absorptivity of dichromate is greater than the absorptivity of bichromate. The fourth wavelength, $440 \mathrm{~nm}$, was selected because the absorptivities of the two chromium(III) species are near their respective peaks and the absorptivities of the three chromium(VI) species are small. The absorptivities of the five species at the selected wavelengths are presented in Table I.

TABLE I. Molar absorptivities for the five chromium species at the four wavelengths chosen for the spectroscopic analytical technique.

\begin{tabular}{lcccc}
\hline & \multicolumn{4}{c}{ Molar absorptivities (L/mol cm) } \\
& \multicolumn{4}{c}{ Wavelength (nm) } \\
\cline { 2 - 5 } \multicolumn{1}{c}{ Chromium species } & $\lambda=328$ & $\lambda=344$ & $\lambda=380$ & $\lambda=440$ \\
\hline Aquated chromium(III) & 0.55 & 1.55 & 9.69 & 9.89 \\
Tris(acetato)chromium(III) & 35.2 & 24.2 & 16.1 & 38.7 \\
Chromate & 602 & 2050 & 4720 & 273 \\
Bichromate & 1080 & 1590 & 822 & 228 \\
Dichromate & 2100 & 3460 & 4480 & 527 \\
\hline
\end{tabular}

TABLE II. Measured and known chromium(VI) concentrations for nine sample solutions made up to test the accuracy of the analytical technique.

\begin{tabular}{lccccc}
\hline Sample & $\begin{array}{c}\mathrm{Cr}(\mathrm{VI}) \\
\text { known } \\
(\mathbf{M})\end{array}$ & $\begin{array}{c}\mathrm{Cr}(\mathrm{III}) \\
\text { known } \\
(\mathbf{M})\end{array}$ & $\begin{array}{c}\mathrm{Cr}(\mathrm{VI}) \\
\text { measured } \\
(\mathbf{M})\end{array}$ & $\begin{array}{c}\mathrm{Cr}(\mathrm{VI}) \\
\text { error } \\
(\mathbf{M})\end{array}$ & $\begin{array}{c}\mathrm{Cr}(\mathrm{VI}) \\
\% \\
\text { error }\end{array}$ \\
\hline A & 0.002498 & 0.002501 & 0.002499 & 0.000001 & 0.04 \\
B & 0.002499 & 0.001500 & 0.002505 & 0.000006 & 0.24 \\
$\mathrm{C}$ & 0.002498 & 0.000501 & 0.002509 & 0.000011 & 0.44 \\
$\mathrm{D}$ & 0.001497 & 0.002500 & 0.001506 & 0.000009 & 0.60 \\
$\mathrm{E}$ & 0.001502 & 0.001499 & 0.001512 & 0.000010 & 0.67 \\
$\mathrm{~F}$ & 0.001498 & 0.000499 & 0.001511 & 0.000013 & 0.87 \\
G & 0.000505 & 0.002501 & 0.000508 & 0.000003 & 0.59 \\
H & 0.000500 & 0.001501 & 0.000506 & 0.000006 & 1.20 \\
I & 0.000505 & 0.000500 & 0.000512 & 0.000007 & 1.39 \\
Average & & & & 0.0000073 & 0.671 \\
\hline
\end{tabular}

Spectroscopic Determination of Chromium(VI). Reaction mixtures contain both unreacted chromium(VI) and produced chromium(III) and have an absorbance spectrum that is the combined absorbance of each species in the reaction mixture. Consequently, the analytical technique was tested on solutions that contained both chromium(III) and chromium(VI). Nine test solutions were prepared that contained known amounts of chromium(VI) $(0.0005$ to $0.0025 \mathrm{M})$ and known amounts of chromium(III) (0.0005 to $0.0025 \mathrm{M}$ ). The chromium(VI) concentration of each test solution was determined with the use of the spectroscopic analytical technique, and the known and measured chromium(VI) concentrations were compared (Table II).

For the nine test solutions, the known and measured chromium(VI) concentrations were all in close agree-ment. An average error of approximately $1 \%$ between known and measured chromium(VI) concentrations was demonstrated. The test solutions contained both chromium(VI) and chromium(III) so that the visible absorbance spectra of the test solutions would be similar to those of reaction mixtures. Consequently, the results of this test show that the analytical technique is capable of accurately determining the chromium(VI) concentration of reaction mixtures.

\section{CONCLUSIONS}

Procedures have been developed to determine the concentration of chromium(VI) during the reduction of chromium(VI) to chromium(III) in the 3.0 to $5.5 \mathrm{pH}$ range. The reaction is run in the presence of an acetic acid/sodium acetate buffer to stop the formation of a brown precipitate containing chromium(VI) and chromium(III). The analytical technique was shown to have an average error of approximately $1 \%$ for solutions containing 0.0005 to $0.0025 \mathrm{M}$ chromium(VI) and 0.0005 to $0.0025 \mathrm{M}$ chromium(III).

\section{ACKNOWLEDGMENTS}

This research was supported by the U.S. Department of Energy; the Tertiary Oil Recovery Project, University of Kansas; and the Department of Chemistry and Medicinal Chemistry, University of Kansas.

1. R. E. Terry, C. G. Huang, D. W. Green, M. J. Michnick, and G. P. Willhite, Soc. Pet. Eng. J. 21, 229 (1981). 
2. C. S. McCool, An Experimental Study of the In Situ Gelation of a Polyacrylamide/Chromium(VI)/Thiourea System in a Porous Medium, Ph.D. Dissertation, University of Kansas, Lawrence (1988).

3. F. H. Westheimer, Chem. Rev. 45, 419 (1949).

4. J. K. Beattie and G. P. Haight, Jr., Progr. Inorg. Chem. 17, 93 (1972).

5. I. Baldea and G. Niac, Inorg. Chem. 7, 1232 (1968).

6. M. I. Edmonds, K. E. Howlett, and B. L. Wedzicha, J. Chem. Soc. A: 2866 (1970).

7. Y. Hojo, Y. Sugiura, and H. Tanaka, J. Inorg. Nucl. Chem. 39, 1859 (1977).

8. A. McAuley and M. A. Olatunji, Can. J. Chem. 55, 3328 (1977).

9. A. McAuley and M. A. Olatunji, Can. J. Chem. 55, 3335 (1977).

10. J. P. McCann and A. McAuley, J. Chem. Soc. Dalton Trans. 783 (1975).

11. K. A. Muirhead and G. P. Haight, Jr., Inorg. Chem. 12, 1116 (1973).

12. K. A. Muirhead, G. P. Haight, Jr., and J. K. Beattie, J. Am. Chem. Soc. 94, 3006 (1972).

13. P. H. Connett and K. E. Wetterhahn, J. Am. Chem. Soc. 107, 4282 (1985).

14. R. Cuthill and C. Atkins, J. Soc. Chem. Ind., London 56, 5T (1937).

15. K. S. Gupta, R. Swarup, and D. N. Sharma, Labdev J. Sci. Tech. 12a, 84 (1974).
16. V. R. S. Rao, Fresenius' Z. Anal. Chem. 249, 189 (1970).

17. B. Singh and B. C. Verma, Z. Anal. Chem. 196, 432 (1963).

18. M. A. Olatunji and A. McAuley, J. Chem. Soc. Dalton Trans. No. $8,682(1975)$.

19. H. G. Linge and A. L. Jones, Aust. J. Chem. 21, 1445 (1968).

20. H. G. Linge and A. L. Jones, Aust. J. Chem. 21, 2189 (1968).

21. L. Spiccia and W. Marty, Inorg. Chem. 25, 266 (1986).

22. B. Jezowska-Trzebiatowska, J. Hanuza, W. Wojciechowski, and J. Nawojski, J. Inorg. Chim. Acta 2, 202 (1968).

23. G. P. Haight, Jr., E. Perchonock, F. Emmenegger, and G. Gordon, J. Am. Chem. Soc. 87, 3835 (1965).

24. R. E. Hamm, R. L. Johnson, R. H. Perkins, and R. E. Davis, J. Am. Chem. Soc. 80, 4469 (1958).

25. J. Y. Tong and E. L. King, J. Am. Chem. Soc. 75, 6180 (1953).

26. C. T. Kenner, Instrumental and Separation Analysis (Charles E. Merrill Publishing Co., Columbus, Ohio, 1973), Chap. 1, p. 35.

27. B. Carnahan, H. A. Luther, and J. O. Wilkes, Applied Numerical Methods (John Wiley \& Sons, New York, 1969), Chap. 5, p. 270.

28. International Mathematical and Statistical Libraries, Vol. 3 (IMSL, Houston, Texas, 1987) 